\title{
Papers
}

\section{Nurse led follow up and conventional medical follow up in management of patients with lung cancer: randomised trial}

Sally Moore, Jessica Corner, Jo Haviland, Mary Wells, Emma Salmon, Charles Normand, Mike Brada, Mary O'Brien, Ian Smith

\begin{abstract}
Objective To assess the effectiveness of nurse led follow up in the management of patients with lung cancer.

Design Randomised controlled trial.

Setting Specialist cancer hospital and three cancer units in southeastern England.

Participants 203 patients with lung cancer who had completed their initial treatment and were expected to survive for at least 3 months.

Intervention Nurse led follow up of outpatients compared with conventional medical follow up.

Outcome measures Quality of life, patients' satisfaction, general practitioners' satisfaction, survival, symptom-free survival, progression-free survival, use of resources, and comparison of costs.
\end{abstract}

Results Patient acceptability of nurse led follow up was high: $75 \%$ (203/271) of eligible patients consented to participate. Patients who received the intervention had less severe dyspnoea at 3 months $(\mathrm{P}=0.03)$ and had better scores for emotional functioning $(\mathrm{P}=0.03)$ and less peripheral neuropathy $(\mathrm{P}=0.05)$ at 12 months. Intervention group patients scored significantly better in most satisfaction subscales at 3, 6, and 12 months $(\mathrm{P}<0.01$ for all subscales at 3 months). No significant differences in general practitioners' overall satisfaction were seen between the two groups. No differences were seen in survival or rates of objective progression, although nurses recorded progression of symptoms sooner than doctors $(\mathrm{P}=0.01)$. Intervention patients were more likely to die at home rather than in a hospital or hospice ( $\mathrm{P}=0.04)$, attended fewer consultations with a hospital doctor during the first 3 months $(\mathrm{P}=0.004)$, had fewer radiographs during the first 6 months $(\mathrm{P}=0.04)$, and had more radiotherapy within the first 3 months $(\mathrm{P}=0.01)$. No other differences were seen between the two groups in terms of the use of resources.

Conclusion Nurse led follow up was acceptable to lung cancer patients and general practitioners and led to positive outcomes.

\section{Introduction}

Despite substantial evidence that intensive follow up after cancer treatment may not lead to improvements in survival or quality of life, is inefficient at detecting recurrence, and is highly cost ineffective, most patients with cancer are routinely seen in outpatient clinics for many years. ${ }^{1-5}$ The high degree of psychological morbidity among cancer patients suggests a need for close monitoring and support; however, little evidence shows that routine follow up in busy clinics actually provides an environment conducive to supporting patients after a diagnosis of cancer. ${ }^{67}$ Doctors and nurses often fail to detect patients' emotional distress, ${ }^{8}$ and patients report that appointments are so "high speed" that they have little time to raise concerns. ${ }^{9}$

This collaborative study evaluated a reconfigured nurse led follow up service for patients with lung cancer. The service was designed to enhance care across primary, secondary, and tertiary sectors and to reduce the burden on patients and acute services by rationalising the numbers of routine hospital appointments and investigations.

\section{Methods}

We conducted the study at a specialist cancer hospital and three local cancer units. Patients with lung cancer who had completed their initial anticancer treatment and were expected to survive for at least three months were invited to participate. Ethical approval was granted at each study site. An independent trials office was responsible for randomisation of patients to either conventional medical follow up or nurse led follow up. For randomisation, patients were stratified according to hospital and treatment intent. An independent data monitoring committee advised on the conduct of the study.

\section{Protocol}

The care of patients randomised to conventional medical follow up remained unchanged. Conventional care consisted of routine outpatient appointments (one post-treatment appointment, then appointments at two or three month intervals) for medical assessment and investigations to monitor disease
Centre for Cancer and Palliative Care Studies, Institute of Cancer Research, Royal Marsden Hospital, London SW3 6JJ

Sally Moore research practitioner Jo Haviland statistician Mary Wells research practitioner

School of Nursing and Midwifery, University of Southampton, Southampton SO17 1BJ Jessica Corner professor of cancer and palliative care

Clinical Trials and Statistics Unit,

Section of

Epidemiology, Institute of Cancer Research, Sutton, Surrey SM2 5NG Emma Salmon statistician

Department of Epidemiology and Public Health,

London School of

Hygiene and

Tropical Medicine, London

WC1A 7HT

Charles Normand professor of health economics

Royal Marsden Hospital, Sutton, Surrey SM2 5PT

Mike Brada reader and consultant in clinical oncology Mary O'Brien consultant in oncology Ian Smith professor of medical oncology

Correspondence to: J Corner j.l.corner@ soton.ac.uk bmj.com 2002;325:1145 
Table 1 Patient characteristics at randomisation. Values are numbers (percentages) unless stated otherwise

\begin{tabular}{|c|c|c|}
\hline \multirow[b]{2}{*}{ Characteristics } & \multicolumn{2}{|c|}{ Follow up } \\
\hline & Nurse led $(n=99)$ & Conventional $(n=103)$ \\
\hline \multicolumn{3}{|l|}{ World Health Organization's performance status: } \\
\hline Normal activity without restriction & $8(8)$ & $4(4)$ \\
\hline Strenuous activity restricted, can do light work & $59(60)$ & $64(62)$ \\
\hline $\begin{array}{l}\text { Up and about } \geqslant 50 \% \text { of waking hours, capable of self } \\
\text { care }\end{array}$ & $32(32)$ & $35(34)$ \\
\hline \multicolumn{3}{|l|}{ Diagnosis: } \\
\hline Non-small cell lung cancer & $74(75)$ & $73(71)$ \\
\hline Limited small cell lung cancer & $8(8)$ & $9(9)$ \\
\hline Extensive small cell lung cancer & $6(6)$ & $12(12)$ \\
\hline Mesothelioma & $8(8)$ & $6(6)$ \\
\hline Not known (no histology) & $3(3)$ & $3(3)$ \\
\hline \multicolumn{3}{|l|}{ Stage: } \\
\hline | or II & $12(12)$ & $14(14)$ \\
\hline IIIa & $14(14)$ & $7(7)$ \\
\hline IIIb & $28(28)$ & $36(35)$ \\
\hline IV & $19(19)$ & $19(18)$ \\
\hline None (small cell) & $14(14)$ & $21(20)$ \\
\hline Mesothelioma & $8(8)$ & $6(6)$ \\
\hline Not known & $4(4)$ & 0 \\
\hline \multicolumn{3}{|l|}{ Comorbid disease: } \\
\hline Chronic obstructive pulmonary disease & $8(8)$ & $9(9)$ \\
\hline Cardiac disease & $29(29)$ & $16(16)$ \\
\hline Pleural effusion & $2(2)$ & $4(4)$ \\
\hline Hypertension & $18(18)$ & $13(13)$ \\
\hline Arthritis & $22(22)$ & $26(25)$ \\
\hline Gastrointestinal disease & $28(28)$ & $20(19)$ \\
\hline Other comorbid disease & $46(47)$ & $47(46)$ \\
\hline
\end{tabular}

Median (interquartile range) item score on EORTC's quality of life core questionnaire and lung cancer module: ${ }^{*}$

\begin{tabular}{lcc}
\hline Physical functioning & $86.7(86.7-93.3)$ & $86.7(86.7-93.3)$ \\
\hline Role functioning & $66.7(33.3-100)$ & $66.7(33.3-83.3)$ \\
\hline Emotional functioning & $75.0(58.3-95.8)$ & $79.2(64.6-91.7)$ \\
\hline Cognitive functioning & $83.3(75.0-100)$ & $83.3(79.2-100)$ \\
\hline Social functioning & $83.3(50.0-100)$ & $66.7(50.0-100)$ \\
\hline Global health status or quality of life & $66.7(50.0-83.3)$ & $58.3(50.0-68.8)$ \\
\hline Fatigue & $33.3(22.2-55.6)$ & $33.3(22.2-47.2)$ \\
\hline Pain & $16.7(0-33.3)$ & $16.7(0-33.3)$ \\
\hline Appetite & $0(0-33.3)$ & $0(0-33.3)$ \\
\hline Financial worries & $0(0-25.0)$ & $0(0-0)$ \\
\hline Dyspnoea & $25.0(16.7-41.7)$ & $25.0(16.7-50.0)$ \\
\hline Cough & $33.3(0-33.3)$ & $33.3(33.3-41.7)$ \\
\hline Haemoptysis & $0(0-0)$ & $0(0-0)$ \\
\hline Peripheral neuropathy & $0(0-33.3)$ & $0(0-33.3)$ \\
\hline Median (interquartile range) score on patients' satisfaction questionnaire:† & \\
\hline Organisation of care & $68.8(62.5-82.8)$ & $71.9(65.6-81.3)$ \\
\hline Information and advice & $72.9(63.0-81.3)$ & $69.4(62.5-77.1)$ \\
\hline Personal experience of care & $77.3(72.7-88.6)$ & $75.0(72.7-86.4)$ \\
\hline Satisfaction with care & $79.5(63.6-99.4)$ & $75.0(59.1-86.4)$ \\
\hline How would you rate support overall?¥ & $90.0(72.0-100)$ & $90.0(74.8-98.3)$ \\
\hline
\end{tabular}

EORTC=European Organisation for Research and Treatment of Cancer.

*EORTC's questionnaires not completed at baseline for two patients who received nurse led follow up and five patients who received conventional follow up.

†Patient satisfaction questionnaire not completed at baseline for two patients who received nurse led follow up and seven patients who received conventional follow up

fMeasured with a $100 \mathrm{~mm}$ visual analogue scale (range 0-100); high scores represent rating of support as good.

progression. Patients were also seen on the basis of need.

Patients randomised to nurse led follow up were allocated to one of two clinical nurse specialists in lung cancer and were assessed monthly by protocol over the telephone or in a nurse led clinic to identify signs of disease progression, symptoms warranting intervention, or serious complications (box). Additional contacts were made as necessary: patients had access to the clinical nurse specialists in the nurse led clinic or by telephone without an appointment. Clinical nurse specialists focused on providing information and support and coordinating input from other agencies or services. The clinical nurse specialist was responsible for the entire care of patients in the nurse led follow up group, unless the patient needed further treatment. The mean number of contacts with patients was three per month: $14 \%$ of these contacts were initiated by patients. The mean length of contact was 23 (range 2-120) minutes. The clinical nurse specialists were prepared for the role by observing outpatient lung cancer clinics and shadowing medical consultants. Medical consultants and nurse academics gave regular clinical supervision sessions for the clinical nurse specialists. Details of the development of the model of nurse led follow up are published elsewhere. ${ }^{10}$

\section{Outcome measures}

Primary outcomes were quality of life and patients' satisfaction at three months. We assessed quality of life at baseline and at monthly intervals by using the European Organisation for Research and Treatment of Cancer's (EORTC) core questionnaire about quality of life and module about lung cancer. ${ }^{11}$ We assessed patients' satisfaction at baseline and at three, six, and 12 months with a questionnaire that incorporated three validated measures and that was tested in a pilot study. ${ }^{12-15}$ We collected data about quality of life and patients' satisfaction until 12 months to assess the long term effectiveness of nurse led follow up. Secondary endpoints included overall survival, symptom-free survival, and progression-free survival. We assessed general practitioners' satisfaction at the end of study participation. We collected data on use of services at three, six, and 12 months for analyses of patterns of use of services and cost effectiveness of nurse led follow up.

\section{Statistical methods}

We summarised the quality of life questionnaire by calculating functioning and symptom subscales as described in the scoring manual. ${ }^{16}$ We used the same method to summarise the questionnaires about

\section{Nurse led follow up}

- Patients have open access to nurse specialists Monday to Friday and contact through open access clinic, telephone, and message pager service

- Telephone assessment or clinic appointment two weeks after baseline, then every four weeks while patient is stable; no routine investigations

- Clinic assessment form to be completed at each clinic appointment or telephone assessment

- Weekly, open access nursing clinics at the three study sites; short notice (same day) appointment system available

- Emphasis on rapid and comprehensive communication with general practitioner and primary healthcare team by telephone, fax, or letter, as appropriate

- Regular discussion with and referral to medical team on detection of any new symptom or rapid worsening of condition

- Documentation from nurse led clinic was held in notes and sent to general practitioner, home care team or hospice, if applicable, and consultant in charge of patient 
patients' and general practitioners' satisfaction. We compared median scores for the quality of life and satisfaction subscales between the groups by using the Mann-Whitney $\mathrm{U}$ test, because distributions of scores were skewed. We calculated subscales as long as a patient had answered at least half of the items. We used a Kaplan-Meier survival analysis to estimate median survival and the log rank test to compare overall survival, symptom-free survival, and progression-free survival. We calculated costs of visits by general practitioners and nursing staff on the basis of information provided by Netten and Curtis, ${ }^{17}$ calculated costs of hospital treatment with reference to standard costs reported by the Department of Health, ${ }^{18}$ and obtained costs of tests and procedures from Stevens et al. ${ }^{19}$ All costs obtained were in sterling, related to 1999-2000, and were from a health and social care perspective. We used unit costs derived from these sources to calculate the total cost per patient for each period of follow up; we compared these costs between the two groups by using the Mann-Whitney U test. We do not present confidence intervals for differences between randomised groups; we used medians because distributions of outcome variables were skewed, and the estimation of confidence intervals for medians is a complicated procedure that is rarely done.

The intended accrual was 200 patients to detect a difference of 10 between mean scores on the patient satisfaction subscales (assuming a standard deviation of $25,80 \%$ power, and $5 \%$ significance, two sided test) and on the subscales of the quality of life core questionnaire and lung cancer module between the two groups. At the primary time point of three months after randomisation (when data were available for 156 patients) the power of the study was slightly lower $(70 \%)$.

\section{Results}

\section{Participants and follow up}

We approached a total of 271 patients to participate in the trial. Of these, $203(75 \%)$ patients agreed to participate and, after informed consent had been obtained, were randomly allocated to receive either nurse led follow up $(\mathrm{n}=100)$ or conventional medical follow up $(n=103)$. We considered patients to be ineligible if they were receiving cancer treatment, were having close medical supervision, or had a poor prognosis or performance status. One patient randomised to nurse led follow up was later found to be ineligible for the study and was excluded; this left 202 patients for analysis.

Sixty eight patients $(25 \%)$ declined to participate (figure). Forty three (16\%) eligible patients preferred to see a doctor; this indicated a high level of acceptance by patients of nurse led care. Most attrition was due to death or ill health.

\section{Comparison between nurse led and conventional medical follow up}

The mean age of patients in each group was 67 (SD 8.8, range 45-89) years. Most patients were men: 74 $(75 \%)$ of those who received nurse led follow up and $66(64 \%)$ of those who received conventional follow up. The clinical characteristics at baseline were similar between groups (table 1), as were scores for quality of life and patient satisfaction at baseline.

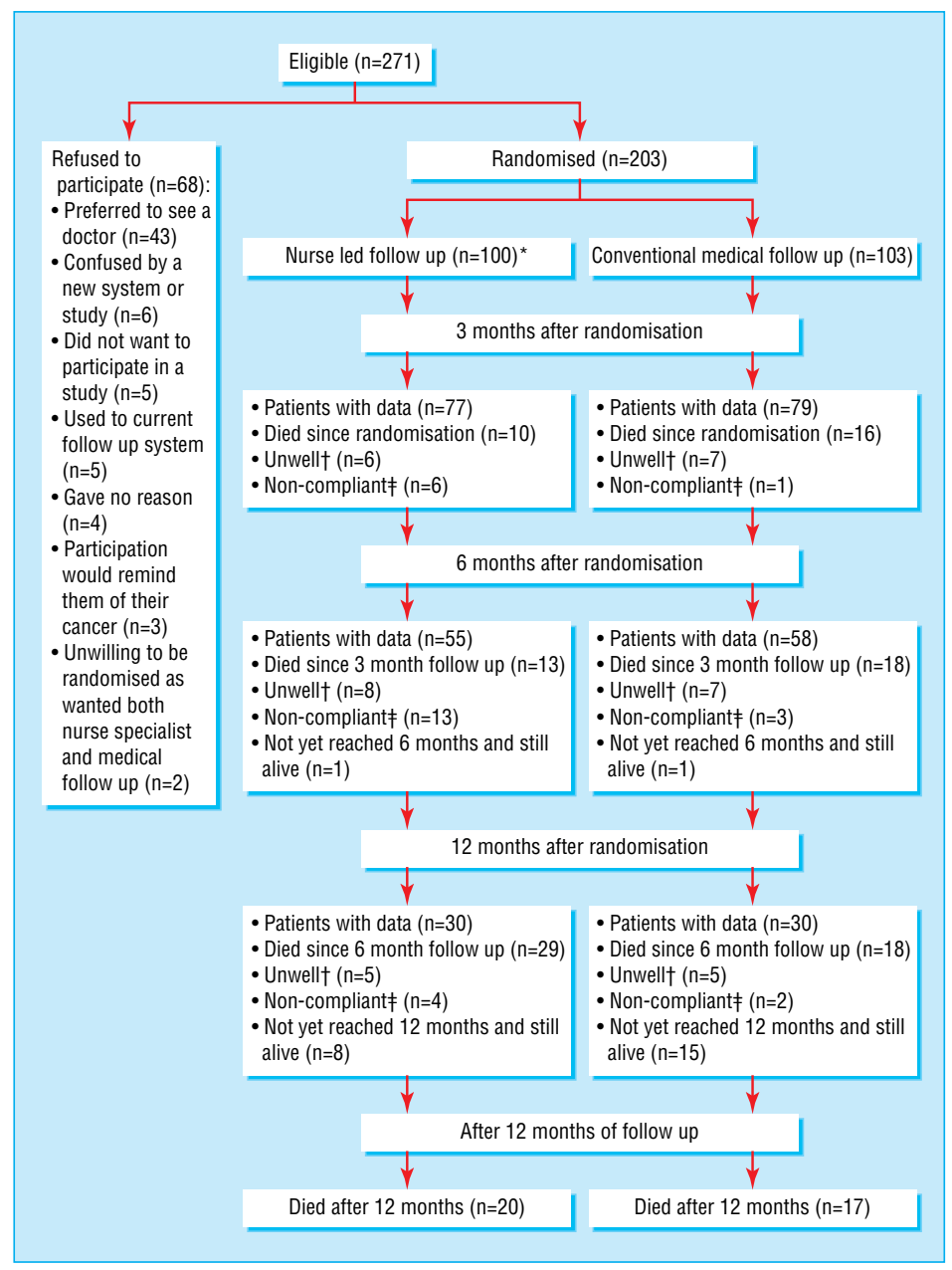

Patient recruitment and follow up. * One patient found to be ineligible after baseline assessment, leaving 99 patients for analysis. †Patient too ill to return questionnaire. $\ddagger$ Patient did not return questionnaire because refused to or gave no reason

Table 2 shows comparisons of scores on the quality of life questionnaire during follow up. Three months after nurse led follow up began, patients rated their dyspnoea as less severe than did patients randomised to conventional medical follow up $(\mathrm{P}=0.03)$. No other statistically significant differences existed at this time or between the randomised groups at six months. At 12 months, patients randomised to receive nurse led follow up had better scores for emotional functioning $(\mathrm{P}=0.03)$ and less peripheral neuropathy $(\mathrm{P}=0.05)$.

Satisfaction with care was generally high. At three months the patients who received nurse led follow up scored significantly higher in each subscale (table 3). At three months $53 / 75(78 \%)$ of patients randomised to nurse led follow up said they would prefer nurse led care if asked to choose, but only $11 / 71(17 \%)$ of patients who received conventional medical follow up would prefer to see a doctor only.

One hundred and forty one $(70 \%)$ patients died during the study: $72(73 \%)$ of those receiving nurse led follow up and $69(67 \%)$ of those receiving conventional medical follow up. When length of follow up from randomisation was taken into account, Kaplan-Meier estimates of median survival time were similar: 9.2 (95\% confidence interval 6.2 to 12.1 ) months versus 10.4 (7.6 to 13.2$)$ months $(\mathrm{P}=0.99)$. 
Table 2 Scores on EORTC's quality of life core questionnaire and lung cancer module at 3,6 , and 12 months after randomisation. Values are medians (interquartile ranges)

\begin{tabular}{|c|c|c|c|}
\hline \multirow[b]{2}{*}{ Item } & \multicolumn{2}{|c|}{ Follow up } & \multirow[b]{2}{*}{ P value* } \\
\hline & Nurse led & Conventional & \\
\hline Three months after randomisation: & $(n=76)$ & $(n=74)$ & \\
\hline Physical functioning & $86.7(86.7-93.3)$ & $86.7(86.7-93.3)$ & 0.22 \\
\hline Role functioning & $66.7(33.3-100)$ & $66.7(33.3-83.3)$ & 0.26 \\
\hline Emotional functioning & $83.3(66.7-97.9)$ & $75.0(66.7-91.7)$ & 0.58 \\
\hline Cognitive functioning & $83.3(66.7-100)$ & $83.3(66.7-100)$ & 0.47 \\
\hline Social functioning & $83.3(66.7-100)$ & $66.7(50.0-100)$ & 0.22 \\
\hline Global health status or quality of life & $66.7(50.0-81.3)$ & $66.7(50.0-83.3)$ & 0.82 \\
\hline Fatigue & $33.3(22.2-44.4)$ & $33.3(22.2-55.6)$ & 0.58 \\
\hline Pain & $16.7(0-33.3)$ & $16.7(0-33.3)$ & 0.89 \\
\hline Appetite & $0(0-33.3)$ & $0(0-33.3)$ & 0.91 \\
\hline Financial worries & $0(0-25.0)$ & $0(0-8.3)$ & 0.99 \\
\hline Dyspnoea & $25.0(16.7-41.7)$ & $33.3(25.0-58.3)$ & 0.03 \\
\hline Cough & $33.3(33.3-66.7)$ & $33.3(33.3-66.7)$ & 0.43 \\
\hline Haemoptysis & 0 & 0 & 0.09 \\
\hline Peripheral neuropathy & $0(0-33.3)$ & $0(0-33.3)$ & 0.45 \\
\hline Six months after randomisation: & $(n=53)$ & $(n=58)$ & \\
\hline Physical functioning & $86.7(80.0-93.3)$ & $86.7(80.0-93.3)$ & 0.27 \\
\hline Role functioning & $66.7(33.3-83.3)$ & $66.7(29.2-83.3)$ & 0.48 \\
\hline Emotional functioning & $91.7(66.7-100)$ & $75.0(66.7-91.7)$ & 0.22 \\
\hline Cognitive functioning & $83.3(66.7-100)$ & $83.3(79.2-100)$ & 0.73 \\
\hline Social functioning & $83.3(33.3-100)$ & $66.7(33.3-83.3)$ & 0.17 \\
\hline Global health status or quality of life & $66.7(50.0-75.0)$ & $62.5(47.9-68.8)$ & 0.27 \\
\hline Fatigue & $33.3(22.2-55.6)$ & $33.3(22.2-66.7)$ & 0.97 \\
\hline Pain & $16.7(0-33.3)$ & $16.7(0-50.0)$ & 0.46 \\
\hline Appetite & $0(0-33.3)$ & $0(0-33.3)$ & 0.32 \\
\hline Financial worries & $0(0-33.3)$ & $0(0-33.3)$ & 0.94 \\
\hline Dyspnoea & $33.3(19.4-58.3)$ & $37.5(16.7-58.3)$ & 0.65 \\
\hline Cough & $33.3(33.3-66.7)$ & $33.3(33.3-66.7)$ & 0.83 \\
\hline Haemoptysis & 0 & 0 & 0.90 \\
\hline Peripheral neuropathy & 0 & $0(0-33.3)$ & 0.32 \\
\hline Twelve months after randomisation: & $(n=26)$ & $(n=29)$ & \\
\hline Physical functioning & $86.7(80.0-93.3)$ & $86.7(83.3-93.3)$ & 0.50 \\
\hline Role functioning & $66.7(45.8-100)$ & $50.0(25.0-66.7)$ & 0.14 \\
\hline Emotional functioning & $91.7(66.7-100)$ & $66.7(54.2-87.5)$ & 0.03 \\
\hline Cognitive functioning & $83.3(50.0-100)$ & $83.3(58.3-100)$ & 0.73 \\
\hline Social functioning & $83.3(62.5-100)$ & $66.7(33.3-91.7)$ & 0.07 \\
\hline Global health status or quality of life & $66.7(50.0-75.0)$ & $58.3(41.7-75.0)$ & 0.42 \\
\hline Fatigue & $33.3(22.2-58.3)$ & $33.3(22.2-66.7)$ & 0.68 \\
\hline Pain & $16.7(0-37.5)$ & $33.3(0-58.3)$ & 0.15 \\
\hline Appetite & $0(0-33.3)$ & $0(0-33.3)$ & 0.50 \\
\hline Financial worries & 0 & $0(0-16.7)$ & 0.59 \\
\hline Dyspnoea & $25.0(14.6-50.0)$ & $50.0(20.8-58.3)$ & 0.06 \\
\hline Cough & $33.3(33.3-66.7)$ & $33.3(16.7-66.7)$ & 0.87 \\
\hline Haemoptysis & 0 & 0 & 0.85 \\
\hline Peripheral neuropathy & 0 & $0(0-33.3)$ & 0.05 \\
\hline
\end{tabular}

EORTC=European Organisation for Research and Treatment of Cancer.

*Mann-Whitney U test.

To test the effectiveness of nurse led follow up, we compared the two groups in terms of differences in the rate of detection of symptomatic progression and objective progression. When length of follow up from randomisation was taken into account, Kaplan-Meier estimates of median time to symptomatic progression were 6.0 (4.7 to 7.3) months in the nurse led follow up group and 10.2 (5.9 to 14.6) months in the conventional medical follow up group $(\mathrm{P}=0.01)$ and times to objective progression were 8.3 (5.5 to 12.2) months and 10.2 (5.9 to 14.5$)$ months $(\mathrm{P}=0.47)$. Therefore, although no evidence showed a difference in objective progression, evidence showed that the nurses recorded symptomatic progression sooner than the doctors; these results are reassuring because they sug- gest that patients who received nurse led care were not at a disadvantage.

Nurse led care changed the pattern of use of services. Patients receiving nurse led follow up had significantly fewer medical consultations with a hospital doctor at three months $(\mathrm{P}=0.004)$, had fewer radiographs taken (including chest radiographs) at three months $(\mathrm{P}=0.04)$ and six months $(23 / 55 v 12 / 57$ had no radiographs; $\mathrm{P}=0.03$ ), and were more likely to have had radiotherapy treatment at three months $(\mathrm{P}=0.01)$ (table 4). Significantly more patients who received nurse led follow up died at home rather than in a hospital or hospice: 29/72 (40\%) patients randomised to nurse led follow up whose place of death was known compared with $14 / 62(23 \%)$ patients randomised to conventional medical follow up $(\mathrm{P}=0.04)$. These differences may be interpreted as evidence of some substitution of nursing for medical inputs and possibly the use of a more appropriate mixture and location of care. Patients who received nurse led care made no greater call on other professionals or services, and no significant difference in readmission rates was seen compared with those who received conventional medical follow up.

Comparison of the overall costs of care for the three periods of follow up showed no significant differences (table 5). Changes in the mixture of services in the first three months of follow up suggest that a larger study might detect some cost differences in this period. The cost of the intervention itself was not included in the comparison, however, because accurate recording of the time spent by nurses and doctors on all patients was not feasible and separation of the elements of the cost of the nurses that related to the research from those that would be included in nurses' normal service was not possible. In the model used in this study, the cost of the nurses was around $£ 150$ per patient month of follow up.

We compared general practitioners' satisfaction with the care of patients under the two models of follow up. Satisfaction questionnaires were completed by $144(73 \%)$ of the 197 general practitioners who were sent them. No significant differences in satisfaction were seen between the patient groups. Overall, 26 (18\%) general practitioners said they would prefer nurse led follow up for future patients, 13 (9\%) would prefer follow up by an oncologist alone, and $66(46 \%)$ would prefer follow up by an oncologist and clinical nurse specialist.

\section{Discussion}

Our findings show that follow up of patients with lung cancer by clinical nurse specialists is safe, acceptable, and cost effective. Such follow up can lead to greater patient satisfaction and more appropriate and timely interventions at the same or no greater cost, with no detriment to quality of life. Without compromising patient safety, nurse led follow up may also reduce the number of routine investigations patients currently have and the burden on outpatient resources and doctors' time.

Acceptability of the nurse led model of follow up was very high and compared favourably with the experience of Grunfeld et al (31\% of breast cancer patients declined randomisation to general prac- 
Table 3 Patient satisfaction at 3, 6, and 12 months after randomisation. Values are medians (interquartile ranges)

\begin{tabular}{|c|c|c|c|}
\hline \multirow[b]{2}{*}{ Item } & \multicolumn{2}{|c|}{ Follow up } & \multirow[b]{2}{*}{$P$ value ${ }^{\star}$} \\
\hline & Nurse led & Conventional & \\
\hline Three months after randomisation: & $(n=75)$ & $(n=71)$ & \\
\hline Organisation of care & $81.3(75.0-93.8)$ & $71.9(65.6-78.1)$ & $<0.001$ \\
\hline Information and advice & $77.1(69.8-89.6)$ & $68.8(58.3-75.0)$ & $<0.001$ \\
\hline Personal experience of care & $77.3(75.0-95.5)$ & $75.0(68.2-80.1)$ & 0.002 \\
\hline Satisfaction with care & $78.4(61.6-100)$ & $70.0(51.1-79.5)$ & 0.005 \\
\hline How would you rate support overall?† & $93.0(80.0-100)$ & $78.0(57.0-94.0)$ & 0.002 \\
\hline Six months after randomisation: & $(n=52)$ & $(n=55)$ & \\
\hline Organisation of care & $83.3(75.0-93.8)$ & $75.0(68.8-78.1)$ & $<0.001$ \\
\hline Information and advice & $75.0(67.9-85.4)$ & $66.7(58.0-75.0)$ & $<0.001$ \\
\hline Personal experience of care & $79.5(72.7-97.7)$ & $75.0(68.2-77.3)$ & 0.001 \\
\hline Satisfaction with care & $79.5(65.9-98.3)$ & $75.0(58.7-89.2)$ & 0.11 \\
\hline How would you rate support overall?† & $89.0(82.8-98.3)$ & $83.0(64.5-96.3)$ & 0.04 \\
\hline Twelve months after randomisation: & $(n=27)$ & $(n=29)$ & \\
\hline Organisation of care & $81.3(75.0-96.9)$ & $75.0(70.3-83.3)$ & 0.01 \\
\hline Information and advice & $75.0(70.8-91.7)$ & $68.8(64.6-77.1)$ & 0.01 \\
\hline Personal experience of care & $79.5(75.0-100)$ & $75.0(70.2-87.5)$ & 0.03 \\
\hline Satisfaction with care & $82.5(72.7-100)$ & $76.1(64.2-85.8)$ & 0.13 \\
\hline How would you rate support overall?† & $93.0(77.0-98.0)$ & $81.5(70.0-95.0)$ & 0.08 \\
\hline
\end{tabular}

*Mann-Whitney U test.

†Measured with a $100 \mathrm{~mm}$ visual analogue scale (range 0-100); high scores represented rating of support as good.

titioner follow up). ${ }^{2}$ Importantly, in our study, no patient in the nurse led follow up group accepted the offer to revert to conventional medical follow up at the end of the data collection period. On the basis of this study, we estimate that approximately half of patients with lung cancer would benefit from similar models of care after treatment.

Currently, although $50 \%$ or more of patients with terminal cancer express a preference to die at home, only $26 \%$ actually do. ${ }^{20-23}$ Forty per cent of patients in our study who received nurse led follow up died at home compared with $23 \%$ of patients who received conventional medical follow up. This compares favourably with a randomised study by Grande et al that evaluated a "hospital at home" service; the authors were unable to conclude that the service led to more patients dying at home. ${ }^{24}$

\section{Limitations}

Replication at other centres in the United Kingdom, with a range of nurse specialists and outside the context of a research study, is essential to confirm the generalisability of the findings. The rate of attrition was high because of death or disability. Such difficulties with recruitment and attrition are recognised problems of research studies conducted with very ill and dying patients. ${ }^{25}$ The number of outcomes analysed in this study would imply that some findings may have occurred by chance. We assessed the primary outcome at three months; the results from patients investigated at six and 12 months should be interpreted with caution.

\section{Conclusions}

The results of this study indicate that nurse led initiatives can be used to reconfigure care to make it more responsive to individual needs, increase patient satisfaction, and reduce the burden of hospital visits and investigations. Any increase in cost is likely to be modest. General practitioners were satisfied with the nurse led model of care.

We especially thank the clinical nurse specialists (Frances Fuller, Majella Wright, and Tanya Courtenay) who provided the nurse led service and the doctors (Nigel Cooke, St Helier Hospital Trust; Andrew Miller, Mayday University Hospital; and Janet Hardy, Royal Marsden NHS Trust) who supported and supervised the clinical nurse specialists. We also thank Robert Souhami and Jenifer Wilson-Barnett for their advice on the conduct of the study and Veronica Varney (St Helier NHS Trust), Rupert Courtenay-Evans and Ruth Whitfield (Mayday University Hospital), Nick Rowell, Barbara Dicks, and Diana Tait (Royal Marsden NHS Trust), Richard Sayer (St George's Healthcare NHS Trust), Warren Stevens (London School of Hygiene and Tropical Medicine), and Jeanette Webber (Macmillan Cancer Relief) for their support.

Contributors: JC and MB had the initial idea. JC initiated the study, participated in setting up the study, supervised the research and clinical nurse specialists, and helped to interpret the data. MW participated in setting up the study, coordinated the first phase of the study, supervised the initial training of the clinical nurse specialists, was responsible for data management and entry during the first part of the study. SM coordinated the second part of the study, supervised the clinical nurse specialists, was responsible for data management, checking, and entry, and helped with the analysis. JH was the main statistical adviser to the study and analysed and presented the data. ES helped with the statistical analysis and presentation of the data. $\mathrm{CN}$ analysed the comparative cost data. MO'B provided medical supervision for the clinical nurse specialists. IS participated in setting up the study. SM, JC, JH, and CN wrote the paper. All authors commented on the first draft. JC and SM are the guarantors.

Funding: NHS Research and Development National Cancer Programme funded the study; Macmillan Cancer Relief funded one of the nurse specialists in lung cancer's posts.

Competing interests: JC is a member of the board of trustees for Macmillan Cancer Relief.

1 Radford JA, Eardley A, Woodman C, Crowther D. Follow up policy after treatment for Hodgkin's disease: too many clinic visits and routine tests? A review of hospital records. BMJ 1997;314:343-6.

2 Grunfeld E, Mant D, Yudkin P, Adewuyi-Dalto R, Cole D, Stewart J, et al. Routine follow up of breast cancer in primary care: randomised trial. $B M J$ 1996;313:665-9.

3 Kievit J, Bruinvels DJ. Detection of recurrence after surgery for colorectal cancer. Eur J Cancer 1995;31A:1222-5.

4 Rosselli Del Turco M, Palli D, Carridi A, Ciatto S, Pacini P, Distante V. Intensive diagnostic follow-up after treatment of primary breast cancer: a randomised trial. JAMA 1994;271:1593-7.

5 GIVIO Investigations. Impact of follow-up testing on survival and health related quality of life in breast cancer patients. JAMA 1994;271:1587-92.

6 Greer S, Moorey S, Baruch JDR, Watson M, Robertson BM, Mason A, et al. Adjuvant psychological therapy for patients with cancer: a prospective randomised trial. BMJ 1992;304:675-80.

7 Maguire P. The psychological impact of cancer. Br J Hosp Med 1985;34:100-3. 
Table 4 Use of services at three months after randomisation. Values are numbers (percentages)

\begin{tabular}{|c|c|c|c|}
\hline \multirow[b]{2}{*}{ Service } & \multicolumn{2}{|c|}{ Follow up } & \multirow[b]{2}{*}{ P value ${ }^{x}$} \\
\hline & Nurse led $(n=76)$ & Conventional $(\mathrm{n}=79)$ & \\
\hline General practitioners' visits since previous assessment: & & & $0.31 \dagger$ \\
\hline 0 & $22(28.9)$ & $34(43.6)$ & \\
\hline 1 & $27(35.5)$ & $18(23.1)$ & \\
\hline 2 & $10(13.2)$ & $10(12.8)$ & \\
\hline$\geqslant 3$ & $17(22.4)$ & $16(20.5)$ & \\
\hline General practitioners' home visits since previous assessment: & & & $0.36 \dagger$ \\
\hline 0 & $63(82.9)$ & $70(89.7)$ & \\
\hline 1 & $10(13.2)$ & $5(6.4)$ & \\
\hline$\geqslant 2$ & $3(3.9)$ & $3(3.8)$ & \\
\hline Social services: & & & 0.85 \\
\hline None & $68(89.5)$ & $68(87.2)$ & \\
\hline Benefits advice, home help, or other & $8(10.5)$ & $10(12.8)$ & \\
\hline District nurse & $18(23.7)$ & $12(15.6)$ & 0.29 \\
\hline Macmillan nurse or home care team & $29(38.2)$ & $20(25.6)$ & 0.14 \\
\hline Other community therapist: & & & $>0.99 \ddagger$ \\
\hline None & $73(96.1)$ & $75(96.2)$ & \\
\hline Physiotherapist, occupational therapist, or other therapist & $3(3.9)$ & $3(3.8)$ & \\
\hline Admissions to hospital or hospice: & & & $>0.99$ \\
\hline 0 & $63(82.9)$ & $66(83.5)$ & \\
\hline$\geqslant 1$ & $13(17.1)$ & $13(16.5)$ & \\
\hline Consultations with hospital doctor & & & $0.004 \dagger$ \\
\hline 0 & $31(40.8)$ & $6(7.6)$ & \\
\hline 1 & $20(26.3)$ & $33(41.8)$ & \\
\hline 2 & $9(11.8)$ & $17(21.5)$ & \\
\hline 3 & $8(10.5)$ & $14(17.7)$ & \\
\hline$\geqslant 4$ & $8(10.5)$ & $9(11.4)$ & \\
\hline Radiotherapy since previous assessment & $13(17.1)$ & $3(3.8)$ & 0.01 \\
\hline Chemotherapy since previous assessment & $2(2.6)$ & $5(6.3)$ & $0.44 \ddagger$ \\
\hline Surgery since previous assessment & $1(1.3)$ & $0(0.0)$ & $0.49 \ddagger$ \\
\hline Changes in drugs or new drugs since previous assessment & $51(67.1)$ & $48(60.8)$ & 0.51 \\
\hline Radiographs since previous assessment: & & & $0.04 \dagger$ \\
\hline 0 & $29(38.2)$ & $13(16.5)$ & \\
\hline 1 & $26(34.2)$ & $42(53.2)$ & \\
\hline$\geqslant 2$ & $21(27.6)$ & $24(30.4)$ & \\
\hline Scans since previous assessment: & & & $0.28 \dagger$ \\
\hline 0 & $49(64.5)$ & $57(72.2)$ & \\
\hline 1 & $21(27.6)$ & $18(22.8)$ & \\
\hline$\geqslant 2$ & $6(7.9)$ & $4(5.1)$ & \\
\hline Consultations with other medical staff, specialists, or therapists & $10(13.2)$ & $13(16.5)$ & 0.73 \\
\hline Patient needed someone with them at home to look after them & $1(1.3)$ & $2(2.5)$ & $>0.99 \ddagger$ \\
\hline
\end{tabular}

${ }^{*} \chi^{2}$ test. $\dagger \chi^{2}$ test for trend. ‡Fisher's exact test.

Table 5 Costs per patient by 3, 6, and 12 months after randomisation. Values are medians (interquartile ranges)

\begin{tabular}{|c|c|c|c|}
\hline \multirow[b]{2}{*}{ Time of follow up } & \multicolumn{2}{|c|}{ Follow up } & \multirow[b]{2}{*}{ P value } \\
\hline & Nurse led & Conventional & \\
\hline \multirow[t]{2}{*}{ Three months } & $(n=76)$ & $(n=79)$ & \\
\hline & 221.50 (60.12-869.62) & $288.50(154.00-671.00)$ & 0.18 \\
\hline \multirow[t]{2}{*}{ Six months } & $(n=55)$ & $(\mathrm{n}=57)$ & \\
\hline & $369.50(56.00-1432.00)$ & $364.00(154.00-1181.25)$ & 0.40 \\
\hline \multirow[t]{2}{*}{ Twelve months } & $(n=29)$ & $(n=29)$ & \\
\hline & $696.50(227.25-2318.75)$ & $744.50(298.00-2362.75)$ & 0.66 \\
\hline
\end{tabular}

*Mann-Whitney U test.

8 Hopwood P, Stephens RJ. Depression in patients with lung cancer: prevalence and risk factors derived from quality-of-life data. J Clin Oncol 2000;18:893-903.

9 National Cancer Alliance. "Patient-centred services"? What patients say. Oxford: NCA, 1996

10 Moore S, Corner J, Fuller F. Development of nurse led follow-up in the management of patients with lung cancer. Nurs Times Res 1999;4: $432-445$

11 Aaronson NK, Ahmedzai S, Bergman B. The European Organisation for Research and Treatment of Cancer QLQ30: a quality of life instrument for use in international clinical trials in oncology. J Natl Cancer Inst 1993;85:365-76.

12 Faithfull S, Corner J, Meyer L, Huddart R, Dearnaley D. Evaluation of nurse-led follow up for patients undergoing pelvic radiotherapy. $\mathrm{Br} J$ Cancer 2001;85:1853-64.
13 Thomas LH, McColl E, Priest J, Bond S, Boys R. The Newcastle satisfaction with nursing scales: an instrument for quality assessments of nursing care. Oual Health Care 1996;5:67-74

14 Wolf MH, Putnam SM, James SA, Stiles WB. The medical interview satisfaction scale: development of a scale to measure patient perceptions of physician behaviour. J Behav Med 1978;1:391-401.

15 Avis M, Bond M, Arthur A Exploring patient satisfaction with out-patient services. J Nurs Manag 1995;3:59-65.

16 Fayers P, Aaronson N, Bjordal K, Sullivan M. EORTC QLQ-30 scoring manual. Belgium: EORTC Study Group on Quality of Life, 1995.

17 Netten A, Curtis L. Unit costs of health and social care. Canterbury: Personal Social Services Research Unit, University of Kent, 2000.

18 Department of Health. The new NHS: 2000 reference costs. Leeds: DoH, 2000. 


\section{What is already known on this topic}

Most patients with cancer are routinely seen in outpatient clinics for many years despite lack of evidence of effectiveness

Doctors and nurses often fail to detect patients' emotional distress, and patients have little time to raise concerns

\section{What this study adds}

Follow up of patients with lung cancer by clinical nurse specialists is safe, acceptable, and cost effective

Both patients and general practitioners were highly satisfied with the nurse led model of follow up
20 Hinton J. Can home care maintain an acceptable quality of life for patients with terminal cancer and their relatives? Palliat Med 1994;8:18396.

21 Townsend J, Frank AO, Fermont D, Dyer S, Karran O, Walgrove A, et al. Terminal cancer care and patients' preference for place of death: a prospective study. BMJ 1990;301:415-7.

22 Dunlop R, Davies RJ, Hockley JM. Preferred versus actual place of death a hospital palliative support team study. Palliat Med 1989;3:197-201.

23 Office for National Statistics. Mortality statistics, general: review of registrar general on deaths in England and Wales, 1993-1995. London: Stationery Office, 1997.

24 Grande GE, Todd CJ, Barclay SIG, Farquhar MC. Does hospital at home for palliative care facilitate death at home? Randomised controlled trial. BMJ 1999;319:1472-5.

25 McWhinney IR, Bass MJ, Donner A. Evaluating a palliative care service: problems and pitfalls. BMJ 1994;309:1340-2.

(Accepted 20 June 2002)

19 Stevens W, Grieve R, Normand C. Costing health care interventions for modelling cost-effectiveness in the UK. London: London School of Hygiene and Tropical Medicine, 2000. 